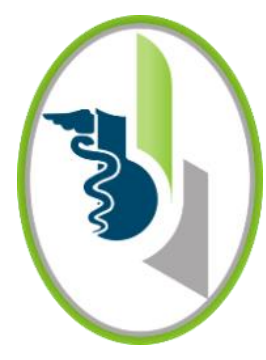

ACCESO ABIERTO
Copyright: (C) 2020. Esta es una reseña bibliográfica de acceso abierto, distribuido bajo los términos de la licencia https://creativecommons.org/licenses/bync-sa/4.0/ la cual permite el uso sin restricciones, distribución y reproducción en cualquier medio, siempre y cuando el original, el autor y la fuente sean acreditados.

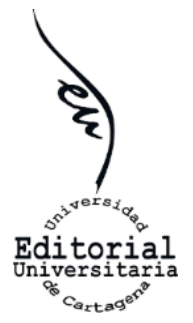

\section{Nivel bajo de resiliencia y los factores asociados en gestantes adolescentes}

\author{
Álvaro Monterrosa Castro, Liezel Ulloque Caamaño
}

El embarazo y la adolescencia son dos condiciones muy sensibles en la vida de la mujer. Cuando se hace necesario dimensionarlas desde el ámbito académico, es necesario detenerse a valorar aspectos cotidianos, implicaciones, factores asociados y elementos que contribuyen a deteriorar el bienestar de la mujer. El embarazo y la adolescencia son situaciones que pueden tornarse problemáticas, sobre todo cuando se juntan, ya que pueden impactar negativamente al individuo y a la comunidad.

Las cifras de embarazo en la adolescencia no se han mejorado significativamente pese a varias iniciativas tomadas a nivel mundial. El embarazo en la adolescencia es considerado

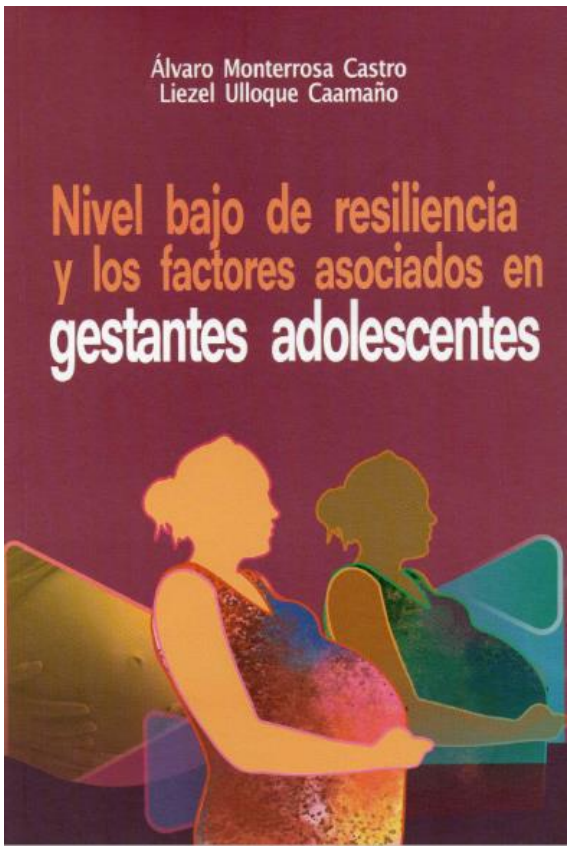
indicador de pobreza y de pérdida de las oportunidades de mejoría en las condiciones de vida, tanto desde el punto de vista del individuo como de su entorno familiar y por tanto social.

El libro presenta los resultados de una investigación en la que se estudió el nivel de resiliencia en 499 embarazadas adolescentes residentes en la ciudad de Cartagena, Colombia, que recibieron atención obstétrica en la Clínica de Maternidad Rafael Calvo, y en la ESE Hospital Cartagena de Indias. El estudio fue realizado por medio de una encuesta que contenía varias escalas que medían aspectos psicosociales, con participación voluntaria y con el consentimiento de las adolescentes embarazadas y de sus acudientes.

El doctor Álvaro Monterrosa Castro es Médico y Especialista en Ginecología y Obstetricia de la facultad de Medicina de la Universidad de Cartagena, Colombia. Actualmente se desempeña como profesor, y director del grupo de investigación Salud de la Mujer, de la facultad de Medicina de la Universidad de Cartagena, Colombia.

La doctora Liezel Ulloque Caamaño es Médico de la facultad de Medicina de la Universidad de Cartagena, Colombia. Magister en Epidemiología de la Universidad del Norte, Barraquilla, Colombia. Actualmente se desempeña como investigadora del grupo de investigación Salud de la Mujer, de la facultad de Medicina de la Universidad de Cartagena, Colombia. 